religion, and his works belong to the great treasury of French literature.

Pascal's invention of the calculating machine, just three hundred years ago, was made while he was a youth of nineteen. He was spurred to it by seeing the burden of arithmetical labour involved in his father's official work as supervisor of taxes at Rouen. He conceived the idea of doing this work mechanically, and developed a design appropriate for this purpose; showing herein the same combination of pure science and mechanical genius that characterized his whole life. But it was one thing to conceive and design the machine, and another to get it made and put into use. Here were needed those practical gifts that he displayed later in his inventions of the wheelbarrow and the omnibus. He must find and test suitable materials for his machine-iron, copper, ivory, ebony, wood. He must find and indeed train suitable workmen, and settle many points by actual trial. His first model was followed by others, and gradual improvements occupied much of his time for the next ten years, in which he strove indefatigably after perfection. He wished also to obtain due reputation and reward from his invention. He obtained royal protection for it, and gained the patronage of many distinguished men. In 1652 he presented one of the last of his fifty models, with a famous letter, to Queen Christina of Sweden. He also wrote a prospectus of his invention that would do credit to a modern school of salesmanship. But other men, despite the royal patent, pirated his invention; and the sight of one of these copies, "a monster", he said, fair on the outside but valueless in use, so disgusted him that he abandoned further interest in his machine.

In a sense, Pascal's invention was premature, in that the mechanical arts in his time were not sufficiently advanced to enable his machine to be made at an economic price, with the accuracy and strength needed for reasonably long use. This difficulty was not overcome until well on into the nineteenth century, by which time also a renewed stimulus to invention was given by the need for many kinds of calculation more intricate than those considered by Pascal.

Consequently until the present century the principal aid to calculation was the table of logarithms published by their Scottish inventor, Napier, in 1614, put into more practical form by Briggs at about the time of Pascal's birth, and afterwards used also in the slide-rule.

These inventions will always retain great practical value, but where extensive and elaborate calculations are necessary the economic method is to use a suitable computing machine. To-day we recall Pascal as the first originator of such machines.

\section{ECONOMY IN THE USE OF FERRO-ALLOYS*}

\author{
By DR. W. H. HATFIELD, F.R.S.
}

$I^{N}$ $\mathrm{N}$ times of peace, particularly if they are of long duration, the qualities and characteristics of that which is produced are the result of tradition and usage, salesmanship, and the developments due to technical progress based on the application of old or

- Paper read on July 25 at the Conference on Mineral Resources and the Attantic Charter arranged by the Division for the Social new knowledge. Tradition, usage, and salesmanship slow up in measure with the inevitable progress towards the realistic efficiency possible through knowledge and the consolidation of technical progress. War and preparation for war insist upon stark efficient realism, and those who prepare for war are given more time to attain to it than those who are unexpectedly called upon to face such conditions. Also, in times of peace, international trade throws open to all countries the world's resources in raw materials and facilities on an economic basis; war rudely disturbs this state of things, and realism in production must then deal with a limited or changed availability of that upon which production cen continue.

These conditions apply at the moment to the production of steel, and particularly to special and alloy steels. Concerted efforts are being made within the industry to attain maximum efficiency based on the availability and changing availability of raw materials and facilities. It will be obvious that tech. nology and technique so developed can be, and will be, projected with advantage into post-war times.

Elements of Interest in Steel Metallurgy.

\begin{tabular}{|c|c|c|c|c|}
\hline Element & Group & $\begin{array}{c}\text { Date } \\
\text { isolated }\end{array}$ & $\begin{array}{c}\text { Metal } \\
\text { isolated by }\end{array}$ & Nationality \\
\hline $\begin{array}{l}\text { Hydrogen } \\
\text { Copper }\end{array}$ & I & $\begin{array}{l}1766 \\
\text { Prehistoric }\end{array}$ & Cavendish & British \\
\hline Zinc & II & Prehistoric & & \\
\hline Aluminium & III & 1854 & H. St. C. Deville & French \\
\hline $\begin{array}{l}\text { Carbon } \\
\text { Silicon } \\
\text { Titanium } \\
\text { Zirconium } \\
\text { Tin } \\
\text { Lead }\end{array}$ & $\begin{array}{l}\text { IV } \\
\text { IV } \\
\text { IV } \\
\text { IV } \\
\text { IV } \\
\text { IV }\end{array}$ & $\begin{array}{l}\text { Prehistoric } \\
1854 \\
1825 \\
1824 \\
\text { Prehistoric } \\
\text { Prehistoric }\end{array}$ & $\begin{array}{l}\text { H. St. C. Deville } \\
\text { Berzelius } \\
\text { Berzelius }\end{array}$ & $\begin{array}{l}\text { French } \\
\text { Swedish } \\
\text { Swedish }\end{array}$ \\
\hline $\begin{array}{l}\text { Nitrogen } \\
\text { Phosphorus } \\
\text { Vanadium } \\
\text { Arsenic } \\
\text { Niobium }\end{array}$ & $\begin{array}{l}\mathbf{v} \\
\mathbf{v} \\
\mathbf{V} \\
\mathrm{V}\end{array}$ & $\begin{array}{l}1772 \\
1669 \\
1830 \\
1240 \\
\\
1801\end{array}$ & $\begin{array}{l}\text { D. Rutherford } \\
\text { H. Brand } \\
\text { Sefstrom } \\
\text { Albertus Magnus, } \\
\text { Bishop of Re- } \\
\text { gensburg } \\
\text { Hatchett }\end{array}$ & $\begin{array}{l}\text { British } \\
\text { German } \\
\text { Swedish } \\
\text { German } \\
\text { British }\end{array}$ \\
\hline $\begin{array}{l}\text { Oxygen } \\
\text { Sulphur } \\
\text { Chromium } \\
\text { Selenium } \\
\text { Molybdenum } \\
\text { Tungsten }\end{array}$ & $\begin{array}{l}\text { VI } \\
\text { VI } \\
\text { VI } \\
\text { VI } \\
\text { VI } \\
\text { VI }\end{array}$ & $\begin{array}{l}1774 \\
\text { Prehistoric } \\
1798 \\
1818 \\
1782 \\
1783\end{array}$ & $\begin{array}{l}\text { Priestley } \\
\text { Vauquelin } \\
\text { Berzelius } \\
\text { P. J. Hjelm } \\
\text { F. D. and H. J. } \\
\text { D'Elhuyar }\end{array}$ & $\begin{array}{l}\text { British } \\
\text { French } \\
\text { Swedish } \\
\text { Swedish } \\
\text { Spanish }\end{array}$ \\
\hline Manganese & VII & 1774 & J. G. Gahn & German \\
\hline $\begin{array}{l}\text { Iron } \\
\text { Cobalt } \\
\text { Nickel }\end{array}$ & $\begin{array}{l}\text { VIII } \\
\text { VIII } \\
\text { VIII }\end{array}$ & $\begin{array}{l}\text { Prehistoric } \\
1742 \\
1751\end{array}$ & $\begin{array}{l}\text { Georg Brandt } \\
\text { Cronstedt }\end{array}$ & $\begin{array}{l}\text { Swedish } \\
\text { Swedish }\end{array}$ \\
\hline
\end{tabular}

It is perhaps of value to consider the twenty-five elements which are of direct interest in the production of steel. In the accompanying table those elements will be found scheduled. They can be divided substantially into four groups, namely, (i) the dominant alloying elements, (ii) the secondary alloying elements, (iii) appertaining and arising essentially as regards process, (iv) for protective coating.

Of these twenty:five elements, knowledge of sevencopper, zinc, carbon, tin, lead, sulphur, and last but most important of all, iron-was bequeathed to us by early civilizations, and a period of some two thousand years passed before we seriously began isolating those which are now so useful. Of the dominant alloying elements, namely, manganese, chromium, nickel, molybdenum, tungsten, cobalt and vanadium, it is of great interest to note that four of these elements were originally isolated in Scandinavia, 
one in France, one in Germany and one in Spain, while of the secondary alloying elements, aluminium, titanium, zirconium, niobium, selenium and copper, three were isolated in Scandinavia, one in France, and one in Britain; the last-mentioned, copper, was employed in prehistoric times.

As regards the elements iron, carbon, and silicon, these are so fundamental as almost to escape notice, but while iron and carbon date from prehistoric times, silicon was only isolated in 1854 in France. Hydrogen, nitrogen, phosphorus, arsenic, oxygen, sulphur are to be looked upon as essentially impurities arising from process, while zinc and tin are used for coating steel in protection against rust (as of course in smaller degree are cadmium and nickel).

In an effort to be able to present a complete picture, I have sought to : $(a)$ schedule the production of the relevant raw materials as regards country of origin ; (b) schedule the countries where the raw materials were smelted or reduced to a usable form ; (c) schedule the origin of the relevant raw materials used by the different steel-making countries. Such statistical evidence merits careful study, and although not sufficiently available for a complete statement, does point to facts of great interest.

The volume of production of an ore in a country is indicative of the achievement of economical winning but not necessarily of the resources prevailing. There may be great quantities of low-grade ore, railways may not be available and population of a suitable character may not be there. Distance, too, is determining from the economic point of view; for example, a great country may find it advantageous to obtain material from a neighbouring country rather than from within the confines of its own extended territory. The geologist locates, the mining engineer advises on practicability, and the industrialist, backed by adequate finance, seeks to develop these relevant deposits. Sound knowledge, enterprise and no little courage is demanded. The collective outcome normally is availability in reasonable relationship to world demand.

Without exception, the steel-making countries do not possess complete essential resources and must import much that is necessary. In normal times, international trade provides the necessary facilities at world prices on a reasonably economic basis. Small countries as well as large ones have successfully developed important steel industries.

To implement the foregoing it is interesting to examine a few cases and then it will be obvious, having in mind present world conditions, that it is essential to use available alloys on their intrinsic technical merits and only to the absolutely essential degree.

As regards the principal alloying elements used in the alloy steel industry, manganese ore, while widely distributed, is produced essentially in Russia, India, West and South Africa and Brazil. Nickel ore production is focused essentially on localized deposits in Canada. Chrome ore, though very widely distributed, is produced in Rhodesia and South Africa, Turkey and the U.S.S.R., and in lesser degree in Cuba, the Philippines, India, Yugoslavia and Greece. Tungsten ore is essentially produced in China, Burma and in less degree in the United States of America and South America. Molybdenum ore production is focused essentially on deposits in the United States. Vanadium ore is produced essentially in Rhodesia and South-West Africa, the United States and Peru. Cobalt ore is derived principally from the Belgian Congo, Rhodesia and Canada.

It will thus be seen that the principal steel-producing countries, the U.S.A., the U.S.S.R., Germany, Great Britain, France, Japan, Belgium, Luxembourg and Scandinavia are dependent upon the normal functioning of international trade and copious transport, particularly in the form of shipping.

Great Britain relies upon importing 30 per cent of her iron ore and the whole of her manganese, chrome, nickel, tungsten, molybdenum, vanadium and cobalt. Germany relies upon importing most of her manganese ore and the whole of her chrome, nickel, tungsten and molybdenum; she claims to recover her vanadium at home. The U.S.A. imports more than 90 per cent of her manganese ore and practically the whole of the chromium, nickel, cobalt and a substantial proportion of her requirements in tungsten. It is thus obvious that the conditions postulated in the fourth clause of the Atlantic Charter did operate even in the period between the two great wars, or how can one explain, for example, the successful iron and steel industries of Scandinavia and Belgium-Luxembourg.

One of the greatest technical achievements is the huge output of iron, and by virtue of the influence which carbon and other elements can confer readily upon it, a very wide range of properties is available. Steel may be soft and ductile, hard and of great strength, wear-resisting, rust- and acid-resisting, heatresisting, may be of high permeability, capable of a high degree of permanent magnetism; may be nonmagnetic, have a high electrical resistance, or a low coefficient of expansion. It may possess various combinations of these and other properties as required. It can be converted by added elements into any of a wide range of tool steels and steels for many special applications. These results are attained by a knowledgeable heat-treatment superposed upon a selected suitable composition.

Some fifteen elements are involved in the production of these various properties, and it will at once be apparent that millions of alloys of various compositions would need to be tested out really to put this phase of metallurgy upon a finally quantitative basis. Thus some properties may be achieved by using different proportions of different elements, and that fact, coupled with other factors operating in the world, has resulted in quite a complexity as regards the number of steels available. The obvious thing is for the producer and user in co-operation to use only those compositions which are most effective and most in sympathy with the availability of the materials.

The problems before such a collaboration are influenced by many variables. There is the peculiar combination of properties required for a particular purpose, achieved by complex compositions which, although they in practice achieve their purpose, have been found to do so by practical trial-that is, by 'trial and error' method-and it is not always easy in a steel containing a number of alloyed elements in different proportions to diagnose the extent to which amounts of each individual element contribute or to what extent the selected superposed heattreatment is responsible for the ultimate result. Again, it can be argued that so long as the necessary mechanical and physical properties are secured, the composition and treatment are of secondary importance; this might truly be argued, were it possible by testing methods alone to ascertain completely 
whether the conditions for a particular service have been achieved. Laboratory tests to simulate the calls of service are valuable, but they are generally incomplete. Even the designer, try as he may, is never sure of being able to postulate completely on paper the conditions which he has to meet and then provide the means of meeting them.

Thus, by practical experimental procedure based on existing knowledge, mechanisms and apparatus are provided, built of materials which by trial are found to serve the purpose. It is, therefore, not a matter of surprise that when success has been painfully achieyed by modifications here and there as dictated by circumstance, the means whereby success has been achieved are fairly rigidly adhered to. When stock is taken in a national emergency, multiplicity of types of material and of design is to be expected. The next step is to facilitate mass production by strictly limiting the number of designs and vastly reducing the number of types of material.

What has been done as regards the metallurgy of steel, particularly as regards special and alloy steels ? In May 1940, the Special and Alloy Steels Committee constituted its Technical Advisory Committee with a mandate to deal with this problem. It was found that the production of the steels was governed by between two and three thousand specifications. The first step was, therefore, a meticulous study which resulted in the sorting out of the whole of the steels covered by the specifications into eighty-five categories essentially upon the basis of mechanical properties, compositions or special functions. The T.A.C. Schedule 1 to 85 did not lend itself to general publication since it was all-embracing, but it permitted. the appropriate authorities and individuals to survey the interesting position thus disclosed.

The main point achieved was that it became possible to measure up needs against availability as regards the essential alloying elements. Means were found by the Steel Control, assisted by the goodwill of the industry and the consumers, to accommodate manufacture with quite reasonable success to changing conditions. Still conditions change, but in the truly indigenous British manner of adaptation to changing circumstance, the means of adaptation now exist which it may be presumed will achieve as much as is possible according to the existing conditions and needs of the moment.

The T.A.C. schedule of eighty-five categories for so many specifications was possible owing largely to the manner in which the same object was being achieved by different or slightly different compositions and treatments. Thus, as will be described, selection was possible of a relatively few appropriate compositions and treatments to facilitate mass production, but at the same time alternative steels became scheduled and so material guidance exists for change with availability as the need arises. How far can results be achieved without alloy conditions? How far can we replace nickel with chromium or chromium with nickel? How and in what eircumstances are molybdenum and vanadium essential ? Can we replace tungsten with molybdenum or molybdenum with tungsten ? Will a modified heat treatment with a different composition give the same characteristics ? A survey of the categories of the schedule assists in answering some of these questions.

In 1941 advantage was taken of the existence of the British Standards Institution to issue document $B S 970 / 1941$, giving in the form of fifty-eight specifications the principal and most useful of the steels in the schedule covering Wrought Special and Alloy Steels for General Engineering purposes in dimensions up to $6 \mathrm{in}$. ruling section. This document was shortly followed by $B S 971$, which implemented the contents of $B S 970 / 1941$ with much technical and other useful data facilitating the successful application of the selected steels; this document sets a precedent in form. At this stage the Steel Controller issued a 'direction' through the British Standards Institution BS970A indicating that, in conformity with existing conditions, certain steels specified in BS970/1941 should in the absence of special sanctions be the steels applied in future programmes. Thus the 'En Series' of war steels entered their useful career. On March 30,1942 , a brochure was issued indexing and correlating the great mass of specifications to the steels of the Direction $970 \mathrm{~A}$ which sought to replace them. Two remaining steps should be mentioned: $B S 970 /$ 1941 was revised and is re-issued as $B S 970 / 1942$, and representatives of all the Services, after deliberation upon the steps already taken, issued through the British Standards Institution Document BS/STA5, which co-ordinates the whole of the requirements of the Services within the terms of reference with the composition and properties of the steels of the 'direction' on the basis of the En Series contained in BS970/1942.

This successful collective effort at unification has only been possible as a result of the firm determination of all parties to attain that which was intended. Finality in present changing circumstances is not possible, but succeeding documents under the ægis of the same authorities will, it is hoped, successfully keep up to date such essential data.

The fortunate Crusader had a superbly efficient Toledo sword of high temper ; that is, the blade had a tensile strength of more than a hundred tons per square inch. This was obtained by the diffusion of carbon into wrought iron, and the steel so produced when heated above the critical point became a solid solution of carbide or carbon in iron; rapidly quenched in water from this temperature the blade was intensely hard and also brittle, but when lightly tempered by reheating to a skilfully selected temperature, material hardness was still retained but was accompanied by a remarkable toughness. Such results can only be obtained in such thin sections; if heavy pieces of such steel are quenched from the hardening temperature, the actual rate of cooling becomes so relatively slow as to allow the solid solution to break down and hardening is not achieved. Nevertheless, modern carbon steels which, different from the steel of medieval times, contain a substantial quantity of manganese, may be hardened and tempered in the form of bars of quite useful sizes with resultant considerable strength and ductility. The exploitation of such material to the greatest practical extent is most desirable at the present time.

The use of a particular composition of steel necessary for a particular application is governed by the strength and properties required and by the sectional area, or to be more correct, the 'ruling section'. If the mass is considerable and the strength required great, a rich alloy steel is essential to ensure success in hardening and therefore the possibility of superposing upon the quenched condition by tempering a desirable toughness associated with the degree of strength required.

In heavy masses where it is desired to obtain properties resulting from hardening and tempering, as much as 5-6 per cent of alloying elements is 
necessary, such as chromium and nickel, and these elements may be used in different proportions with a material degree of interchangeability, according to availability. Under such conditions a small proportion of molybdenum is desirable essentially to preserve higher values in resistance, when required, to the notched bar impact test and in part to reinforce the hardening properties. As the mass or section decreases, less alloy is needed, and this aspect is given quantitative guidance on alternate bases in $B S 970 / 1942$ and BS971. Thus the heavy use of alloying elements should be restricted according to mass.

The remarks so far refer to the development of strength and hardness in different degree by the processes of hardening and tempering. There are a considerable number of instances where alloys used in greater quantity produce important and entirely different characteristics. 13-30 per cent of chromium and 2-20 per cent of nickel, together with lesser amounts of other elements, are necessary to produce rust-, acid- or heat-resisting steels. Large quantities of tungsten and/or molybdenum, together with material quantities of chromium, vanadium and cobalt, are used to produce high-speed cutting steels. High percentages of manganese are necessary to produce the wear-resisting properties of the austenitic manganese steel. Many other special purpose applications could be quoted. The use of such steels, owing to their high alloy content, is being carefully watched and controlled.

The problem is a considerable one : namely, how at the present time to cater for a greatly increasing demand for steels of the necessary properties, with a changing availability and a considerable deficiency in some of the essential elements. Never has a more interesting technical situation developed, for solution by scientific and technical minds.

Autocracy in science or technology is as deadly as in the political field. In these efforts within the steel industry, our work is being advanced by the friendly and enthusiastic collaboration of many minds; the co-ordination of different points of view has resulted in, and is operating, a workable procedure. Stark efficient realism is necessarily our theme.

\section{THE TOTAL SOLAR ECLIPSE OF OCTOBER I, 1940}

$\mathrm{T}$ HE results obtained by the joint expedition of the National Geographic Society and the National Bureau of Standards to Brazil to observe the total solar eclipse of October, 1940, are given in enviable detail in a beautifully produced monograph appearing as No. 2 in the Solar Eclipse Series of Contributed Technical Papers of the National Geographic Society. The site selected by the two organizations was at Patos, a town of 10,000 inhabitants in north-east Brazil, some 160 miles from the coast. The programme included photographing the corona in monochrome and in colour; measurements of the brightness and polarization of the corona ; a spectro. graphic study of the flash- and coronal-spectra from $10,000 \mathrm{~A}$. to $3,000 \mathrm{~A}$.; measurements of sky brightness, from which the physical condition of the upper atmosphere was to be deduced; precise contact-time observations ; and radio sounding of the ionosphere for the purpose of studying the effects produced by the eclipse in the upper atmosphere. Much of the apparatus taken out was specially designed for this expedition, and it must have been an anxious time when, after a clear dawn, clouds began to form at sunrise. Occasional clear patches allowed glimpses of the narrowing crescent of the sun after first contact, but during totality (8.45 a.m. local time) the sky in the neighbourhood of the sun was completely veiled, though the clouds were thin enough to allow a view of the inner corona, and an excellent flashspectrum was obtained just after third contact. The photographic observations of the corona and the photometric measurements on the sky illumination were ruined, however, and even the radio observa. tions, though independent of the weather, were somewhat marred by a technical mishap. However, much valuable information has been derived from those parts of the programme which could be carried through, and the monograph contains seven papers on various aspects of the results.

I. C. Gardner describes the design and construction of the eclipse apparatus, the main items of which were two corona cameras, one equipped with a rotatable polarizing screen, and two slitless concavegrating spectrographs intended to record the chromospheric and coronal spectra in the ranges $3,000-$ $5,500 \mathrm{~A}$. and 5,000-10,000 A. respectively. All the apparatus was operated by vacuum or electric lines, either automatically or by push-button control, and the exposures were made on standard aeroplane $(240 \mathrm{~mm}$.) roll film. Instead of using mountings which can be adjusted for future eclipses in different latitudes, cheap welded frames were made in angleiron or steel tube, the intention being to provide the proper elevation in future by remaking the appropriate parts of the frame. Fine adjustment was provided by mounting the frames on ordinary screw jacks in concrete.

The short-wave spectrograph was operated manually when a sudden break in the clouds occurred at the end of totality, and a single first-order spectrogram $1 \mathrm{~m}$. long (dispersion 2.4 A./mm.) was secured, showing the chromospheric emission lines superposed on an over-exposed Fraunhofer spectrum. Unfortunately, a mishap to a control switch on the other spectrograph prevented a simultaneous long. wave record being obtained. A contribution by C. C. Kiess gives the results obtained by measurement of the spectrogram : wave-lengths, estimated intensities and characters, origins and term combinations are listed for nearly 1,100 chromospheric lines in the region $3,227-5,398 \mathrm{~A}$. The Balmer series is traced from $\mathrm{H} \beta=\mathrm{H}_{4}$ to $\mathrm{H}_{29}$, but there is no sign of the ionized helium line at 4,686 A.

As in all modern astrophysical work, calibration marks were impressed on the spectrograms with the view of deriving absolute intensities for the emission lines. The intensity calibration was performed by means of a standard tungsten-ribbon lamp operated at $2,917^{\circ} \mathrm{K}$. The intensity distribution in the spectrum of this lamp, as received at the focal surface of the eclipse spectrograph, was measured at $100 \mathrm{~A}$. intervals between $3,450 \mathrm{~A}$. and $5,350 \mathrm{~A}$. by R. Stair and W. W. Coblentz, the work being described in full in one of the papers comprising the monograph. C. C. Kiess and C. J. Humphreys, in another contribution, utilize this calibration in making intensity measurements on the $b$ group of $\mathrm{MgI}$ in the green, on the $H$ and $K$ lines of $\mathrm{Ca} I I$ in the ultraviolet, and on the Balmer lines of hydrogen. As is well known, the intensity decrement along the 